\title{
Muscle strength evaluation of limb dominance in prepubescent swimmers boys and girls
}

Authors' Contribution: A Study Design B Data Collection C Statistical Analysis D Data Interpretation E Manuscript Preparation F Literature Search G Funds Collection

 \\ Gizem İrem Kınıkıı ${ }^{1}$ ACD \\ ${ }^{1}$ Faculty of Physical Therapy and Rehabilitation, Hacettepe University, Ankara, Turkey \\ ${ }^{2}$ Faculty of Sports Science, Hacettepe University, Ankara, Turkey
}

\section{abstract}

Background: The aim of this study was to compare the lower limb muscle strength in terms of gender and limb dominancy in prepubescent swimmers.

Material and methods: Seventy-four prepubescent swimmers (mean age: $11.01 \pm 1.58$ years; 42 boys; 32 girls) who were training for at least 8 hours a week and without current lower limb pain participated in the study. Isometric muscle strength of lower limb was measured by hand-held dynamometry. Independent samples-t test was used to determine the difference between genders, while paired samples-t test was used for dominant-nondominant side comparison. The significance level was accepted as $p<0.05$

Results: Knee flexion $(p<0.001)$, extension $(p<0.001)$ and ankle dorsiflexion $(p=0.003)$ muscle strength were stronger on the dominant side than on the non-dominant side. Knee flexion/extension strength ratio was similar $(p=0.957)$; while ankle plantar flexion/dorsiflexion strength ratio was significantly different $(p=0.011)$. Boys swimmers had stronger isometric muscle strength in the dominant side together with knee flexion $(p=0.018)$ and knee flexion extension strength ratio $(p=0.007)$ than girls swimmers.

Conclusions: Boys swimmers had higher dominant side knee flexion muscle strength compared to female peers. Gender and lower limb dominancy might be important for lower limb muscle strength to show varieties in prepubescent swimmers before planning a training program

Key words: lower limb, knee, ankle, muscle strength, swimming.

\section{article details}

Article statistics: Word count: 2,244; Tables: 3; Figures: 2; References: 26

Received: April 2020; Accepted: June 2021; Published: September 2021

Full-text PDF: http://www.balticsportscience.com

Copyright @ Gdansk University of Physical Education and Sport, Poland

Indexation: Celdes, Clarivate Analytics Emerging Sources Citation Index (ESCI), CNKI Scholar (China National Knowledge Infrastructure), CNPIEC, DOAJ, EBSCO - Central \& Eastern European Academic Source, EBSCO - SPORTDiscus, EBSCO Discovery Service, Google Scholar, Index Copernicus, J-Gate, Naviga (Softweco, Primo Central (ExLibris), ProQuest - Family Health, ProQuest - Health \& Medical Complete, ProQuest - Illustrata: Health Sciences, ProQuest Nursing \& Allied Health Source, Summon (Serials Solutions/ProQuest, TDOne (TDNet), Ulrich's Periodicals Directory/ ulrichsweb, WorldCat (OCLC)

Funding: This research received no specific grant from any funding agency in the public, commercial, or not-for-profit sectors.

Conflict of interests: Authors have declared that no competing interest exists.

This is an open access article distributed under the terms of the Creative Commons Attribution-Non-Commercial-NoDerivatives 4.0 International (https://creativecommons.org/licenses/by-nc-nd/4.0/), which permits use, distribution, and reproduction in any medium, provided the original work is properly cited, the use is non-commercial and is otherwise in compliance with the license. 


\section{INTRODUCTION}

Swimming is a competitive sport that is in high demand among young people and aims to complete a certain distance in the shortest time possible [1]. In this sport, where water provides significantly more resistance to athletes' movements, swimmers are constantly asked to generate propulsion [2]. In addition to the upper limb movements, lower limb movements also play an important role in swimming. A high lower limb muscle strength is required to achieve good performance. In particular, in swimming, sufficient and balanced lower and upper extremity muscle strength is needed to push the body in the water and to move rapidly [3].

Asymmetries in the lower limbs are determined by strength deficits between the two limbs [4]. Asymmetries in the lower limbs have been the subject of recent studies concerning many different contact and non-contact sports. Strength asymmetries between the dominant and nondominant limbs or between agonist-antagonist muscle groups (reciprocal strength ratio imbalances) have been reported in sports with asymmetric kinetic patterns like soccer [5], basketball [6], and volleyball [7] as well as in sports with symmetric motor patterns like running and cycling [8]. However, it is noteworthy that there are no studies examining lower limb muscle strength asymmetry in prepubescent swimmers in the literature.

Few studies have examined lower limb muscle strength between girls and boys in prepubescence. These studies reported that there were no significant gender differences in peak torque of the knee flexor and extensor in untrained volunteers [9, 10]. In addition, lower limb muscle strength has been reported to be similar in untrained boys and girls aged 10 to 12 years [11]. Mameletzi et al. [12], who examined gender differences in isokinetic strength of knee muscles in 10-12-year-old swimmers, found no significant differences between boys and girls in the knee muscle strength. Contrary to these studies, a more recent study has reported that lower extremity asymmetries are more common in female athletes than in male athletes, especially in the pubescent period [13].

According to these studies in the literature, the results regarding strength asymmetries between the dominant and nondominant limbs by gender are uncertain due to conflicting findings, and the gender effect on lower limb strength between the dominant and nondominant sides is not well documented. Moreover, to our knowledge, lower extremity muscle strength has not been studied sufficiently in athletic populations who have been trained in activities requiring specific skills, such as swimming, according to gender and dominance. Since it has been reported that adolescents at this age are more likely to be injured due to changes in their bodies $[14,15]$, it may be important to examine the lower extremity muscle strength in terms of the dominance of limbs and determine whether there is a gender difference in prepubescent swimmers. We hypothesized that there would be varieties in lower limb muscle strength according to gender and limb dominancy in prepubescent swimmers.

\section{MATERIAL AND METHODS}

\section{PARTICIPANTS}

In this cross-sectional study in which lower limb muscle strength was examined in prepubescent swimmers, 32 girls and 42 boys practicing swimming were evaluated. Before the evaluations, an informative meeting was held for coaches, swimmers and their parents. All swimmers were directed to work by the team coaches of the ANKA sports swimming club. Before the evaluations, all participants filled out a questionnaire containing demographic information (hand dominance, swimming experience, etc.) (Table 1). Informed consent was obtained from all swimmers and their parents before collecting data. Measurements were made at the Beytepe Olympic Swimming Pool. This study was approved in advance by Hacettepe University Non-Interventional Clinical Research Ethics Committee with the decision number GO20/858. 
This study involved volunteer swimmers who trained at least 8 hours a week, who did not miss training for more than 2 months in any period. The swimmers who had a history of lower limb injury and felt pain during the evaluation were excluded from the study. The dominant limb was assessed via asking foot preference for activities such as kicking a ball.

Table 1. Physical characteristics of the swimmers

\begin{tabular}{lccc} 
& Boys $(\mathrm{n}=42)$ & Girls $(\mathrm{n}=32)$ & $\mathrm{p}^{*}$ \\
\hline Age (years) & $10.93 \pm 1.61$ & $11.12 \pm 1.55$ & 0.615 \\
Body height $(\mathrm{cm})$ & $146.38 \pm 11.07$ & $150.09 \pm 11.42$ & 0.163 \\
Sitting height $(\mathrm{cm})$ & $76.20 \pm 5.56$ & $77.72 \pm 6.66$ & 0.360 \\
Lower leg length $(\mathrm{cm})$ & $68.53 \pm 6.74$ & $71.54 \pm 6.41$ & 0.114 \\
Weight $(\mathrm{kg})$ & $38.14 \pm 8.30$ & $39.84 \pm 9.69$ & 0.419 \\
Body Mass Index $\left(\mathrm{kg} / \mathrm{m}^{2}\right)$ & $17.63 \pm 2.27$ & $17.40 \pm 1.96$ & 0.633 \\
Swimming experience (years) & $4.37 \pm 1.99$ & $4.7 \pm 1.95$ & 0.334 \\
\hline Note. ${ }^{*}>0.05$. & &
\end{tabular}

Note. ${ }^{p}>0.05$

\section{MeAsurements}

A MicroFet 2 hand-held dynamometer (Model-01165, Lafayette Instrument Company, Lafayette IN, USA) device, which is valid and reliable for swimmers, was used for isometric muscle strength measurement [16]. The advantages of this device are that it is simple to use, easy to carry, and its measurements are not time-consuming, and low cost.

Muscle strength measurement was made before the morning swimming training session and was evaluated using a standard break-test method. Each swimmer involved in the study was informed about the measurement of muscle strength before starting the assessment. In order to ensure correct movement, the swimmers were asked to perform a submaximal contraction against the evaluator's hand before the test [17]. Measurements were made according to the "break test" technique. In this protocol, the clinician pushes the dynamometer until motion is released in the joint so that he can beat the maximum muscle strength [18].

Swimmers were positioned prone for knee flexion (FL), ankle plantar (PLF) and dorsi flexion (DFL) muscle strength measurement. For the knee flexion measurement, the limb on the measured side was positioned at 90 degrees flexion. The swimmers were asked to apply the maximum force in the opposite direction to the resistance of the researcher who made the measurement (Figure 1a-b).

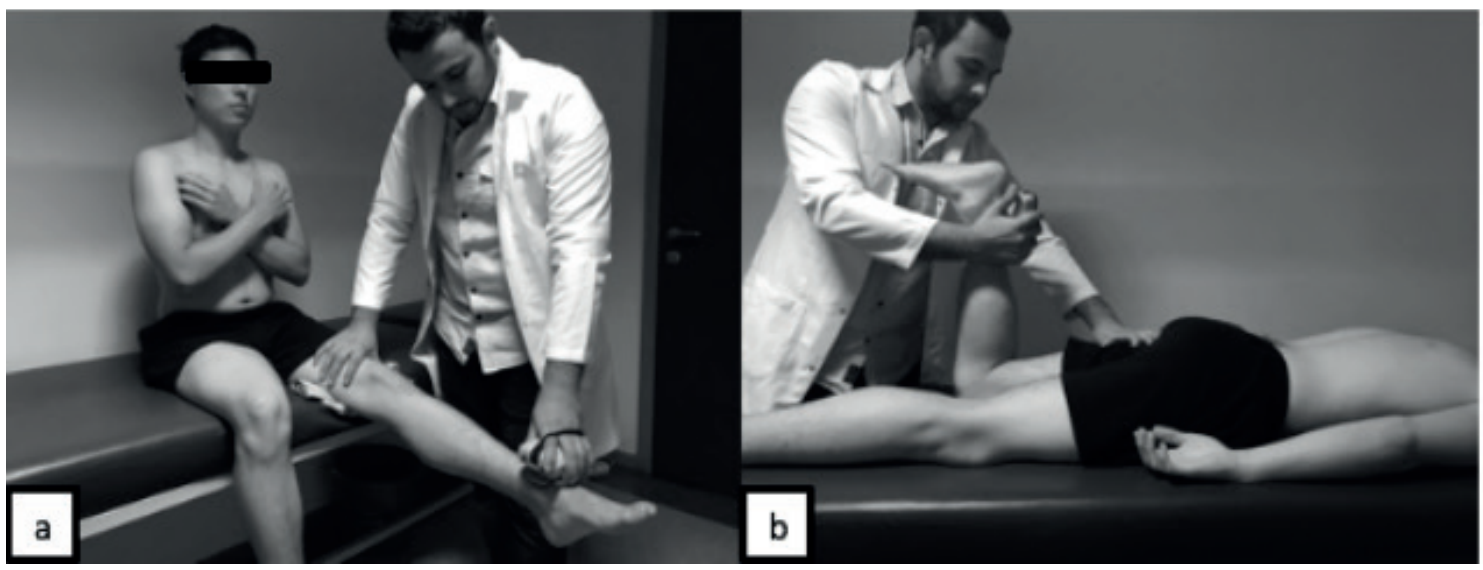

Fig. 1. Knee flexion and extension 
For the measurement of ankle plantar and dorsiflexion muscle strength, the swimmers' feet were positioned from the ankle to hang from the end of the measuring table. Measurements were made by asking the swimmers to keep the ankle in a neutral position (Figure 2a-b).



Fig. 2. Ankle dorsiflexion and plantar flexion

For the measurement of knee extension (EX) muscle strength, the individuals were seated with their legs hanging from the knee at $90^{\circ}$ flexion, feet free, arms crossed on the chest and not supported. During the knee extension muscle strength measurement, after swimmers completed the maximum knee extension, the leg was stabilized with one hand of the clinician. In all muscle strength measurements, the swimmers were asked to maintain their maximum isometric contraction for 5 seconds after the relevant movement was completed. The average of 3 consecutive maximum contraction measurement values performed at 30-second intervals was taken and recorded in kilograms. The average maximum contraction strength was standardized based on body weight to compare lower limb muscle strength. FL: EX and PFL: DFL ratios were calculated for each swimmer from the standardized values and were reported.

IBM SPSS 20.0 package program was used for data analysis. Whether variables show normal distribution was determined by visual (histogram and probability graphs) and analytical methods (Kolmogorov-Smirnov / Shapiro-Wilk tests). Descriptive analysis was shown with the mean and standard deviation for numerical variables.

Since the variables showed normal distribution, in the comparison of muscle strength according to gender, the t-test was used in independent samples. In the dominant and non-dominant side comparisons, the dependent sample t-test was used because the data were distributed normally. Type- 1 error level was used as $5 \%$ for statistical significance.

\section{RESULTS}

Physical characteristics of the swimmers participating in the study were similar ( $p>0.05)$ (Table 1). A comparison of the knee flexion, extension, ankle dorsiflexion, plantar flexion muscle strength of the dominant and non-dominant sides of swimmers is shown in Table 2. While there was a statistically significant difference between swimmers' dominant and non-dominant side knee flexion, extension, ankle dorsiflexion muscle strength values $(p<0.05)$; there was no difference in ankle plantar flexion muscle strength values $(p>0.05)$. While there was no statistically significant difference in the dominant and non-dominant side knee flexion extension ratio ( $p>0.05)$, there was a significant difference in the ankle plantar flexion dorsiflexion strength ratio $(\mathrm{p}<0.05)$. 
Table 2. Comparison of muscle strength and ratios of the dominant and non-dominant side

\begin{tabular}{|c|c|c|c|c|c|}
\hline$n=74$ & $\begin{array}{l}\text { Dominant } \\
X \pm S D\end{array}$ & $\begin{array}{c}\text { Non-Dominant } \\
X \pm S D\end{array}$ & Deficit (\%) & $\mathrm{t}$ & $p$ \\
\hline \multicolumn{6}{|l|}{ Knee $(\mathrm{kg})$} \\
\hline - FL & $21.50 \pm 4.62$ & $19.48 \pm 4.05$ & $8.73 \pm 12.07$ & 6.809 & $<0.001^{*}$ \\
\hline - EX & $20.21 \pm 4.57$ & $18.38 \pm 4.57$ & $8.52 \pm 13.50$ & 5.868 & $<0.001^{*}$ \\
\hline FL:EX & $1.09 \pm 0.26$ & $1.09 \pm 0.24$ & $-1.25 \pm 15.81$ & -0.054 & 0.957 \\
\hline \multicolumn{6}{|l|}{ Ankle (kg) } \\
\hline - PFL & $26.94 \pm 5.61$ & $26.92 \pm 6.52$ & $-0.35 \pm 15.04$ & 0.031 & 0.975 \\
\hline - DFL & $27.22 \pm 4.90$ & $25.93 \pm 5.39$ & $4.48 \pm 12.65$ & 3.123 & $0.003 *$ \\
\hline PFL:DFL & $0.99 \pm 0.15$ & $1.05 \pm 0.21$ & $-6.69 \pm 20.17$ & -2.615 & $0.011 *$ \\
\hline
\end{tabular}

Note. ${ }^{*} \mathrm{p}<0.05$ Paired Sample t-test; SD: Standard Deviation; FL: Flexion; EX: Extension; PFL: Plantar flexion; DFL: Dorsi flexion.

A comparison of swimmers' knee flexion, extension, ankle dorsiflexion and plantar flexion muscle strength by gender is shown in Table 3. While there was a statistically significant difference between boys and girls in favor of boys in the dominant side knee flexion muscle strength $(p=0.018)$ and knee FL:ER $(p=0.007)$, there was no statistically significant difference between boys and girls swimmers in the knee extension, ankle dorsiflexion, plantar flexion muscle strength, and PFL:DFL ( $\mathrm{p}>0.05)$.

Table 3. Comparison of muscle strength and ratios according to gender

\begin{tabular}{ccccccc} 
& \multicolumn{3}{c}{ Dominant $\mathrm{X} \pm \mathrm{SD}$} & \multicolumn{3}{c}{ Non-Dominant $\mathrm{X} \pm \mathrm{SD}$} \\
\cline { 2 - 7 } $\mathrm{n}=74$ & Girls $(\mathrm{n}=32)$ & Boys $(\mathrm{n}=42)$ & $\mathrm{p}$ & Girls $(\mathrm{n}=32)$ & Boys $(\mathrm{n}=42)$ & $\mathrm{p}$ \\
\hline $\mathrm{FL}(\mathrm{kg})$ & $20.15 \pm 2.97$ & $22.53 \pm 5.36$ & $0.018^{*}$ & $18.74 \pm 3.17$ & $20.04 \pm 4.57$ & 0.154 \\
$\mathrm{EX}(\mathrm{kg})$ & $20.42 \pm 4.28$ & $20.04 \pm 4.82$ & 0.720 & $18.82 \pm 4.76$ & $18.04 \pm 4.45$ & 0.473 \\
$\mathrm{FL} / \mathrm{EX}$ & $1.00 \pm 0.15$ & $1.16 \pm 0.31$ & $0.007 *$ & $1.03 \pm 0.21$ & $1.14 \pm 0.26$ & 0.051 \\
PF (kg) & $27.09 \pm 6.48$ & $26.82 \pm 4.90$ & 0.845 & $26.58 \pm 6.42$ & $27.19 \pm 6.67$ & 0.697 \\
DF (kg) & $27.23 \pm 5.07$ & $27.21 \pm 4.82$ & 0.985 & $25.61 \pm 5.98$ & $26.19 \pm 4.94$ & 0.660 \\
PFL/DFL & $1.00 \pm 0.19$ & $0.99 \pm 0.12$ & 0.758 & $1.06 \pm 0.22$ & $1.05 \pm 0.21$ & 0.856 \\
\hline
\end{tabular}

\section{DISCUSSION}

The results of this study demonstrated that boy and girl prepubescent swimmers are similar in lower limb muscle strength except knee flexion strength and FL:EX in favor of boy swimmers. In addition, knee flexion, extension, ankle dorsiflexion muscle strength and PFL:DFL were higher in the dominant side in prepubescent swimmers although the knee FL:EX and plantar flexion muscle strength were similar in both sides.

The muscular strength imbalance between the dominant and non-dominant side is usually known as a factor that may affect performance and increase the risk of injury $[19,20]$. Although there is no definite consensus on the magnitude of the percentage of dominant and non-dominant side strength deficits, it was stated in a study with soccer players that this rate being more than $10 \%$ may pose a risk of injury [4, 21]. Dalamitros et al. [22] studied 11 boy adolescent swimmers (age: 14.82 \pm 0.45 years) before and after a regular combined swimming period. In the comparison of the dominant non-dominant side of the muscle strength values before treatment, the authors found a $2.58 \%$ deficit in flexion muscle strength and $2.89 \%$ in extension muscle strength. In our study, muscle strength deficit was found between the dominant and non-dominant sides in knee flexion strength by $8.73 \%$ and in knee extension strength by $8.52 \%$. The reason for the high asymmetry percentage is that swimmers in our study have low swimming experience and, therefore, 
adequate muscle adaptation may not have developed yet. Accordingly, the strength deficit between the dominant and non-dominant side presented in the current study can be defined as normal. Future studies should focus on these factors as the presence of asymmetry can result from a wide variety of factors such as overtraining, technique, developmental factors, laterality and effect of the injury [23].

Gender differences seem to be explained by the differences in the amount of training in many top-level athletes such as skiers, swimmers, runners, soccer players [24]. Buśko et al. [25], who examines the differences in knee flexion and extension muscle strength according to gender, found a difference in favor of men in both flexion and extension muscle strength. They stated that this difference in muscle strength was caused by the fact that boys have more muscle mass. By contrast, in our study, girls and boys swimmers showed similarities in lower limb muscle strength, except for the dominant side knee flexion muscle strength and flexion extension strength ratio. The reason for this may be that the swimmers in our study continue their development due to their pre-adolescence period. While the swimmers' average age in the study by Buśko et al. was $21.9 \pm 3.2$, the average age of the swimmers in our study was $11.01 \pm 1.58$.

Mameletzi et al. [12], who examined sex differences in isokinetic strength of knee muscles in 10-12-year-old swimmers, found no significant differences between boys and girls for the extension, flexion strength, and flexion-extension strength ratio. By contrast, in our study, there was a difference in favor of boys in knee flexion, extension muscle strength, and flexion-extension strength ratio. The reason for this difference in knee flexion in favor of boys swimmers might be due to the fact that boys have more type 2 muscle fibers [26]. In the analysis by gender, knee extension ankle plantar and dorsiflexion muscle strength were surprisingly similar. This may be because the boys and girls swimmers evaluated in the study did not complete the maturation period (Tanner stage 1-2). Since the swimmers evaluated in the study are in the pre-adolescent period, muscle development and growth continue. Adequate and balanced muscle development is important with maturation.

\section{LIMITATION}

The most important limitation of our study is that due to the low average age of the swimmers evaluated in the study, their maturation stages were not completed. This may have an impact on the results of muscle strength assessment by gender. Since these data reflect this age group, long-term follow-up studies are needed to demonstrate the muscle strength change in boys and girls swimmers due to growth with a hormonal change. Another limitation is that swimmers do not have pre-season data. When the literature is examined, studies with swimmers generally include follow-up studies. In our study, it would be better to have evaluation data for pre-season muscle strength in order to interpret the changes that occurred during the swimming season.

\section{CONCLUSION}

In conclusion, we compared the lower limb muscle strength in terms of gender and limb dominance in prepubescent swimmers. We found that while boy and girl prepubescent swimmers share similarities in knee extension, ankle plantar, dorsiflexion muscle strength and plantar flexion dorsiflexion strength ratio, boy and girl prepubescent swimmers show differences in knee flexion strength and F/E ratio in favor of boy swimmers. In addition, we found that lower limb muscle strength was asymmetrical between dominant and nondominant sides in prepubescent swimmers. Our findings concerning lower extremity muscle strength according to gender and limb dominance may be helpful in planning a training program of prepubescent swimmers. However, since the measured parameters 
of prepubescent swimmers will change very quickly with advancing age and will be completely different, our findings should be interpreted carefully and not generalized to other young athletes of different ages who are interested in various sports.

\section{ACKNOWLEDGEMENTS}

The authors would like to thank all the swimmers, their parents and coach Efe Orhan of the ANKA sports club and thank the Hacettepe University for providing equipment assistance for this study. The authors have no conflict of interest to declare. The study complies with the current laws of the country in which it was conducted.

\section{REFERENCES}

[1] Struyf F, Tate A, Kuppens K, Feijen S, Michener LA. Musculoskeletal dysfunctions associated with swimmers' shoulder. Br J Sports Med. 2017;51(10):775-780. https://doi.org/10.1136/bjsports-2016-096847

[2] Smith DJ, Norris SR, Hogg JM. Performance evaluation of swimmers. Sports medicine. 2002;32(9):539-554. https:// doi.org/10.2165/00007256-200232090-00001

[3] Yamamura C, Zushi S, Takata K, Ishiko T, Matsui N, Kitagawa K. Physiological characteristics of well-trained synchronized swimmers in relation to performance scores. Int J Sport Med. 1999;20(04):246-251. https://doi. org/10.1055/s-2007-971125

[4] Fousekis K, Tsepis E, Vagenas G. Lower limb strength in professional soccer players: profile, asymmetry, and training age. J Sport Sci Med. 2010;9(3):364-273.

[5] Rahnama N, Lees A, Bambaecichi E. A comparison of muscle strength and flexibility between the preferred and non-preferred leg in English soccer players. Ergonomics. 2005;48(11-14):1568-1575. https://doi. org/10.1080/00140130500101585

[6] Fort-Vanmeerhaeghe A, Montalvo AM, Sitja-Rabert M, Kiefer AW, Myer GD. Neuromuscular asymmetries in the lower limbs of elite female youth basketball players and the application of the skillful limb model of comparison. Phys Ther Sport. 2015;16(4):317-323. https://doi.org/10.1016/j.ptsp.2015.01.003

[7] Markou S, Vagenas G. Multivariate isokinetic asymmetry of the knee and shoulder in elite volleyball players. Eur J Sport Sci. 2006;6(01):71-80. https://doi.org/10.1080/17461390500533147

[8] Carpes FP, Mota CB, Faria IE. On the bilateral asymmetry during running and cycling-A review considering leg preference. Phys Ther Sport. 2010;11(4):136-142. https://doi.org/10.1016/j.ptsp.2010.06.005

[9] BA De Ste Croix M, Armstrong N, Welsman J, Sharpe P. Longitudinal changes in isokinetic leg strength in 10-14-yearolds. Ann Human Biol. 2002;29(1):50-62. https://doi.org/10.1080/03014460110057981

[10] Seger JY, Thorstensson A. Muscle strength and electromyogram in boys and girls followed through puberty. Eur J Appl Physiol. 2000;81(1):54-61. https://doi.org/10.1007/PL00013797

[11] De Ste Croix M, Armstrong N, Chia M, Welsman J, Parsons G, Sharpe P. Changes in short-term power output in 10-to 12-year-olds. J Sport Sci. 2001;19(2):141-148. https://doi.org/10.1080/026404101300036352

[12] Mameletzi D, Siatras T. Sex differences in isokinetic strength and power of knee muscles in 10-12 year old swimmers. Isokinetics Exerc Sci. 2003;11(4):231-237. https://doi.org/10.3233/IES-2003-0152

[13] Myer GD, Brent JL, Ford KR, Hewett TE. Real-time assessment and neuromuscular training feedback techniques to prevent ACL injury in female athletes. Strength Cond. 2011;33(3):21-35. https://doi.org/10.1519/SSC.0b013e318213afa8

[14] Ogden JA. Skeletal injury in the child: Springer Science \& Business Media; 2006.

[15] Shanmugam C, Maffulli N. Sports injuries in children. Br Med Bull. 2008;86(1):33-57. https://doi.org/10.1093/bmb/ $\operatorname{ldn} 001$

[16] Coinceicao A, Parraca J, Marinho D, et al. Assessment of isometric strength of the shoulder rotators in swimmers using a handheld dynamometer: A reliability study. Acta Bioeng Biomechan. 2018;20(4):113-119.

[17] Thorborg K, Petersen J, Magnusson S, Hölmich P. Clinical assessment of hip strength using a hand-held dynamometer is reliable. Scand J Med Sci Sport. 2010;20(3):493-501. https://doi.org/10.1111/j.1600-0838.2009.00958.x

[18] Van der Ploeg R, Oosterhuis H. The" make/break test" as a diagnostic tool in functional weakness. J Neurol Neurosurg Psychiatry. 1991;54(3):248-251. https://doi.org/10.1136/jnnp.54.3.248

[19] Knapik JJ, Bauman CL, Jones BH, Harris JM, Vaughan L. Preseason strength and flexibility imbalances associated with athletic injuries in female collegiate athletes. Am J Sport Med. 1991;19(1):76-81. https://doi. org/10.1177/036354659101900113

[20] Yoshioka S, Nagano A, Hay DC, Fukashiro S. The effect of bilateral asymmetry of muscle strength on the height of a squat jump: a computer simulation study. J Sport Sci. 2011;29(8):867-877. https://doi.org/10.1080/02640414.20 11.568512

[21] Tol JL, Hamilton B, Eirale C, Muxart P, Jacobsen P, Whiteley R. At return to play following hamstring injury the majority of professional football players have residual isokinetic deficits. Br J Sports Med. 2014;48(18):1364-1369. https://doi.org/10.1136/bjsports-2013-093016

[22] Dalamitros AA, Manou V, Christoulas K, Kellis S. Knee muscles isokinetic evaluation after a six-month regular combined swim and dry-land strength training period in adolescent competitive swimmers. J Hum Kinetics. 2015;49(1):195-200. https://doi.org/10.1515/hukin-2015-0121

[23] Sanders RH, Thow J, Fairweather M. Asymmetries in swimming: Where do they come from. J Swimming Sci. 2011;18:1-11. 
[24] Ristolainen L, Heinonen A, Waller B, Kujala UM, Kettunen JA. Gender differences in sport injury risk and types of inju-ries: a retrospective twelve-month study on cross-country skiers, swimmers, long-distance runners and soccer players. J Sport Sci Med. 2009;8(3):443-451. https://doi.org/10.1111/j.1600-0838.2009.00955.x

[25] Busko K, Gajewski J. Muscle strength and power of elite female and male swimmers. Balt J Health Phys Act. 2011;3(1):13-18. https://doi.org/10.2478/v10131-011-0001-9

[26] Jansson E, Hedberg G. Skeletal muscle fibre types in teenagers: relationship to physical performance and activity. Scand J Med Sci Sport. 1991;1(1):31-44. https://doi.org/10.1111/j.1600-0838.1991.tb00268.x 